\title{
«¿Y esto a quién se lo cuento, al ayuntamiento?»: trabajadores sociales entre la vocación y la burocracia. Un análisis antropológico del modelo de intervención de los Servicios Sociales a partir de la etnografía de una red asistencial madrileña
}

\author{
Should I tell the City Council about this? Social Workers between \\ Vocation and Bureaucracy. An Ethnography of a Public Social Welfare \\ Network in Madrid \\ Montserrat CAÑEdo RodRíGuez \\ Departamento de Antropología Social y Cultural[ UNED \\ mcanedo@fsof.uned.es
}

Recibido: $15 / 03 / 2011$

Revisado: $24 / 03 / 2011$

Aceptado: 20/06/2011

Disponible on line: 29/09/2011

\begin{abstract}
Resumen
A partir de la descripción etnográfica del funcionamiento de una red de asistencia social pública en el centro de Madrid, e incluyendo de manera especial el testimonio y el análisis de las prácticas de sus trabajadores sociales, este artículo pretende mostrar empírica y localizadamente de qué maneras y en qué sentido el modelo de intervención de los Servicios Sociales del Estado reproduce la marginalidad social, y cómo sus profesionales, situados en la frontera de la institución, viven en carne propia las contradicciones implícitas en dicho modelo.

Palabras clave: etnografía de los Servicios Sociales, trabajadores sociales, marginalidad urbana, Lavapiés (Madrid).
\end{abstract}

\begin{abstract}
Starting from an ethnographic description of how a public social welfare network in the center of Madrid works, paying special attention to the testimony and an analysis of the practice of its social workers, this article seeks to show, empirically, how and in what sense public policies reproduce social marginality and how social workers, located at the institution's frontier, experience very intimately all the contradictions implicit in the system.

Keywords: ethnography of Social Services, social workers, urban marginality, Lavapiés (Madrid).

Referencia normalizada: Cañedo Rodríguez, M. (2011). «¿Y esto a quién se lo cuento, al ayuntamiento?”: trabajadores sociales entre la vocación y la burocracia. Un análisis antropológico del modelo de intervención de los Servicios Sociales a partir de la etnografía de una red asistencial madrileña». Cuadernos de Trabajo Social, 24: 135-153.

Sumario: Introducción. 1. Definición del objeto de estudio y justificación metodológica. 2. Los rasgos clave de un modelo asistencial: el ajuste de las «demandas» a los «recursos» y la «derivación». 3. La relación entre profesionales: lógica burocrática y frustración. 4. Marginalidad social: significado y efectos. 5. Conclusiones: ¿la dimisión del Estado? 6. Referencias bibliográficas.
\end{abstract}

\section{Introducción}

Desde el año 2000 al 2002 la autora de este texto llevó a cabo en Lavapiés, un barrio popular del centro de Madrid, un trabajo de cam- po intensivo que fue la base de su tesis doctoral en Antropología social. El barrio estaba siendo objeto de una ambiciosa política pública de rehabilitación urbanística, a partir de 
un diagnóstico de «crisis» y «degradación» más o menos compartido por vecinos, políticos y técnicos de diversas instituciones del Estado que conocían la realidad -urbanística, económica, social- del barrio. El consenso articulado sobre la necesidad de una intervención pública en Lavapiés dio paso, sin embargo, a medida que la política de rehabilitación se implementaba, a la constitución de una arena política donde la disputa y el conflicto se articularon alrededor de qué significaba y cómo debía llevarse a cabo dicha «rehabilitación». Se trató de una arena política en la que participaron muy diversos actores locales: desde señeras asociaciones de vecinos herederas del movimiento ciudadano de los años 1970, hasta miembros de varias casas y centros sociales «okupas» del barrio, técnicos de la Oficina de la Rehabilitación, asociaciones y ONGs de carácter asistencial y cultural, comunidades de vecinos de distinto tipo, etc. Una de las cuestiones más candentes, al hilo de la rehabilitación del barrio, fue el profundo debate crítico sobre hasta qué punto aquélla estaba dando lugar a un proceso de «gentrificación» que expulsaba o podía acabar por expulsar a gran parte de la tradicional población del barrio, sustituyéndola por nuevos residentes con más recursos y un perfil socio-económico distinto ${ }^{1}$. En la arena política de la rehabilitación, en relación a la cuestión implícita en el debate de la mayor necesidad, carencia o falta de recursos de (una parte de) la población de Lavapiés en comparación con la población de otros barrios de Madrid, un ámbito institucional y el grupo de personas en él implicadas se revelaron como actores importantes: los Servicios Sociales y sus profesionales, encabezados por la figura del trabajador social. Ellos son también los personajes principales en la etnografía que sirve de base a este texto.

\section{Definición del objeto de estudio y justi- ficación metodológica}

Una parte del desarrollo de mi trabajo de campo en Lavapiés, en el que se fundamenta la aportación aquí presentada, consistió en la observación participante del funcionamiento de la red de asistencia social en el barrio, articulada en torno a varios centros institucionales municipales y a otras asociaciones no gubernamentales. Concretamente los nodos principales de esta red eran el Centro de Servicios Sociales «Puerta de Toledo» del ayuntamiento, el Centro de Salud de Lavapiés, el Centro de Ancianos de Embajadores, el Centro Comunitario del Casino de la Reina y varias asociaciones que realizan trabajo social en el entorno como actividad principal o secundaria (la asociación de vecinos La Corrala y Cáritas, entre otras de menor presencia). El desempeño de una actividad de voluntariado, en colaboración con una de las trabajadoras sociales de la zona, me permitió realizar la observación participante durante varios meses en estos centros de atención institucional, así como en los espacios privados y públicos de vida y relación social de varios de sus «usuarios» (en el argot institucional). La etnografía se completó con la realización de quince entrevistas en profundidad a profesionales situados en distintos puntos de esta red, trece entrevistas a destinatarios de la ayuda, y dos grupos de discusión con población anciana participante habitual de las actividades del centro de Embajadores. El grueso de la observación, las entrevistas y los grupos se llevaron a cabo en 2003, con una parte del trabajo de campo (observación y tres entrevistas), realizada posteriormente, en 2010, al objeto de atender a cambios significativos que hubieran podido producirse en relación al objeto de estudio y que se revelaron mínimos.

La cuestión fundamental que guió la observación y el análisis era la constatación de un discurso compartido y sostenido -en entrevistas individuales, conversaciones informales y situaciones de variado tipo- por parte de un número significativo de los trabajadores sociales de la red ${ }^{2}$. Un discurso preñado de una gran carga emocional, que se modulaba de manera distinta en unos trabajadores y en otros, pero que apuntaba a la vivencia com-

1 Sobre la rehabilitación de Lavapiés, así como sobre las características socio-demográficas del barrio puede consultarse Cañedo, 2006 y Pérez Quintana, 2010. Ver también la nota 4 de este texto.

${ }^{2}$ Hablo aquí en un sentido amplio e inclusivo, pues la figura genérica del trabajador social se concreta en la práctica en distintos tipos de profesionales con distintos perfiles y atribuciones. 
partida e iba más allá de lo individual y de una tensión estructural en el desarrollo de su desempeño profesional. La nota emocional protagonista era casi siempre un declarado sentimiento de frustración, que se traducía en una ambivalencia respecto a la valoración del trabajo realizado y a la satisfacción con el mismo. Si, por un lado, no dejaba de afirmarse tanto la «necesidad» del Trabajo Social como la disposición continuada «a dar más de lo que uno debería dar en un trabajo», por el otro, numerosas conversaciones terminaban en serias dudas sobre la eficacia última de la ayuda social, y en la confesión de algo que se parece bastante a lo que los psicólogos caracterizan últimamente con la etiqueta del «síndrome del trabajador quemado», y que llevaba frecuentemente a mis interlocutores a un amplio despliegue de quejas, formuladas muchas veces de forma imprecisa contra «los de arriba», «la organización institucional»o «el sistema». Lo recurrente en este tipo de discurso, así como su consistencia, me hizo preguntarme por :las condiciones sociales que lo fundan, y en último extremo por la luz que el punto de vista de este grupo arroja sobre el tratamiento que el Estado da a lo que define como necesidad social, a través de la institución de los Servicios Sociales. El objeto de estudio es, de este modo, la posición estructural del trabajador social en relación con la propia institución de los Servicios Sociales, las tensiones que de ella derivan, tal y como son vividas por aquél, y el valor que un análisis de este tipo puede tener para repensar los presupuestos fundamentales del modelo de atención que sostienen los Servicios Sociales públicos.

Mi interés por presentar este análisis ante un público lector potencial no sólo de antropólogos sino de profesionales y expertos en Trabajo Social es obvio. También implica asumir el riesgo de apuntar descripciones y análisis, tal vez excesivamente familiares o tal vez extemporáneos, desde el punto de vista de los intereses de la comunidad de teóricos y practicantes del Trabajo Social. Quizás incluso deje sin abordar cuestiones que pudieran resultar más atractivas que las que verdaderamente abordo. En ese sentido la contribución de este texto es modesta. No contempla la representatividad estadística -aunque sí tipológicadel perfil de profesional que describe. Aun- que detalla el funcionamiento de las prácticas, tareas y actividades en cada fase o nivel de la intervención social en los centros de atención descritos, no incorpora un análisis de los datos cuantitativos relativos al número, frecuencia y tipo de demandas atendidas, que podrían servir sin duda para aquilatar el valor de la afirmación del «desbordamiento de trabajo» que los profesionales refieren. Tampoco se analizan con la extensión que el tema merece los puntos de vista sobre la intervención social y los Servicios Sociales enunciados por los sujetos que reciben la ayuda, puntos de vista que sólo aparecen en el texto ocasionalmente y de manera indirecta. Todas estas líneas de indagación sin duda enriquecerían un estudio más profundo del tema propuesto. Sin embargo creo que la aportación de este trabajo mantiene, no obstante, su valor.

A partir de un trabajo de campo antropológico lo que explícitamente se propone es un análisis de la cuestión concreta ya enunciada. La tesis fundamental, que se irá desarrollando a lo largo del texto, es que la particular frustración de estos técnicos del Trabajo Social tiene que ver con el desajuste entre los objetivos declarados de la institución de los Servicios Sociales públicos, y los resultados obtenidos en la práctica a partir de un determinado modelo de intervención, que es el predominante, así como a partir de una escasez de recursos muy palpable. Ambos elementos limitan el margen de maniobra del trabajador social, al tiempo que los objetivos de la institución -y las demandas, explícitas o implícitas, de los usuarios- lo desbordan con expectativas muy ambiciosas. Esa contradicción es vivida en primera persona por estos trabajadores de la ayuda social, a menudo como un drama, o al menos como una tensión que recorre todo su desempeño profesional.

Una última nota en este apartado. La metodología antropológica es fundamentalmente cualitativa. Aunque ello no impida utilizar para propósitos específicos la técnica de la encuesta, dicha metodología está presidida por el bien conocido «trabajo de campo», que implica una experiencia de convivencia prolongada y sobre el terreno del investigador con los grupos de actores sociales implicados en relación al objeto de estudio elegido. No aspira la antropología a la representatividad estadística, sino 
a la comprensión y la explicación de la lógica social que funda no sólo los discursos sino también las prácticas de los actores -que no pocas veces desmienten a aquéllos y que se encuentran, además, sobredeterminadas y no son reducibles a fáciles equivalencias en términos de causa-efecto-. El trabajo de campo requiere un uso intensivo de la observación participante, la entrevista abierta y en profundidad y -más ocasionalmente- el grupo de discusión, herramientas a través de las cuales el antropólogo va perfilando su objeto de estudio a partir de un característico desplazamiento entre las perspectivas etic y emic. En tanto quiere -en cierto modo, y obviando ahora los matices que esta afirmación requiere- hacerse eco de la pluralidad de las voces de los agentes sociales (y no sólo hacer audible la del investigador), la escritura antropológica demanda la presencia de la cita directa de los informantes, y también incorpora la descripción de ambientes y situaciones, en un estilo que diferencia a esta disciplina de otras, pero que de ninguna manera compromete en sí mismo su «cientificidad», como a veces se afirma desde el desconocimiento de sus fundamentos epistemológicos ${ }^{3}$.

\section{Los rasgos clave de un modelo asisten- cial: el ajuste de las «demandas» a los «re- cursos» y la «derivación»}

La definición, que ofrece la vigente Ley de Servicios Sociales de la Comunidad de Ma- drid, de su finalidad dice textualmente en su artículo 2: «promover el bienestar de las personas, prevenir las situaciones de riesgo y compensar déficits de apoyo social, centrando su interés en los factores de vulnerabilidad o dependencia que, por causas naturales o sobrevenidas, se puedan producir en cada etapa de la vida y traducirse en problemas personales» (Ley 11/2003 de Servicios Sociales de la Comunidad de Madrid). La amplitud y la vaguedad de la finalidad institucional, tal y como se enuncia, se pone también de manifiesto en referencias a la promoción de una «vida digna» o al «derecho de la persona a realizarse como ser social» (Idem.) A pesar de esa virtual universalidad que, con respecto al destinatario de los Servicios Sociales, contempla la ley, lo cierto es que su figura, aunque plural, tiene unos contornos socio-culturales definidos, incluso geográficamente. Así por ejemplo, tenemos el caso del barrio de Lavapiés ${ }^{4}$, cuya configuración ya histórica como espacio urbano marginal -en él resuenan aún ecos de esa figura de la imaginación urbana burguesa que fueron los «barrios bajos»-, hace que no resulte extraño que la presencia de los Servicios Sociales sea significativamente mayor, y que estén sometidos a una mayor demanda, con respecto a lo que sucede en otros barrios de la ciudad.

La misma ley que regula los Servicios Sociales madrileños reserva para la Administra-

${ }^{3}$ Con esta breve y sumaria referencia a la especificidad del modo de producción de conocimiento de la Antropología, esto es, de los presupuestos, métodos y escritura característicos de la misma, pretendo al mismo tiempo situar a los posibles lectores no antropólogos ante este texto, y responder por anticipado a un tipo de crítica que se produce demasiadas veces en las relaciones inter o trans-disciplinares; una crítica que no tiene en cuenta el ámbito científico desde el que la aportación objeto de la misma se ha producido. La antropología en absoluto pretende reproducir o glosar opiniones captadas al azar, sino dar cuenta - por decirlo en la terminología de Pierre Bourdieu- de la lógica que funda los campos sociales (como sistemas de relaciones entre posiciones) y los habitus (como sistemas de disposiciones de los sujetos), que dan coherencia o sentido a los discursos y las prácticas que los distintos sujetos sociales enuncian y desarrollan. (Bourdieu, 1993).

${ }^{4}$ Lavapiés pertenece oficialmente al barrio de Embajadores, el más meridional de los barrios del distrito centro de Madrid. Con una población que ha oscilado en la última década entre los cuarenta y los cincuenta mil vecinos. Una serie sumaria de datos puede mostrar por qué es una de las áreas con mayor demanda de asistencia social del distrito. La tasa de desempleo estaba en 2008 siete puntos por encima de la media de la ciudad, mientras la propiedad de la vivienda se sitúa en un 57\%, muy por debajo del 83\% de media en Madrid. La tasa de envejecimiento (similar a otras zonas del centro) es alta: un $22,7 \%$ de los residentes tienen más de 65 años. Del mismo modo se trata de uno de los barrios con mayor presencia de inmigración extranjera, con un 33,2\% en 2008 (Pérez Quintana, 2010). El desempleo, la ancianidad -unida a bajas rentas y lejanía familiar-, y la inmigración reciente son en la práctica variables positivamente relacionadas con la condición de usuarios de los servicios sociales. 
ción el rótulo «Centro de Servicios Sociales», que se aplica a los espacios físicos que funcionan como nodos centrales de la red municipal de asistencia social, organizada sobre una base territorial (por distritos y barrios). El mayor de los dos Centros de Servicios Sociales que tiene el Ayuntamiento de Madrid en el distrito Centro (el que da cobertura a los barrios de Sol, Palacio, Cortes y Embajadores) se encuentra situado en los límites del área de Lavapiés, siendo ésta una de las zonas que dispone de más personal asignado. Este centro, conocido popularmente como «el de La Paloma» por estar ubicado en un inmueble en la calle de dicho nombre (casi en la misma Puerta de Toledo), es el punto de referencia de los Servicios Sociales públicos en el área. Como queda establecido en la citada ley, es el elemento que centraliza toda una red de instancias públicas (que dependen administrativamente del área de Servicios Sociales, pero también tienen algunas competencias la de Sanidad, Educación, Empleo, o Vivienda) que funcionan de manera coordinada en ella. También la iniciativa privada en la esfera de la asistencial social queda legislativamente supeditada a (y en muchos casos es subvencionada por) la Administración Pública, por lo que igualmente la asociación de vecinos y algunas otras de atención a menores o a inmigrantes tienen en el Centro de la Paloma un eje de referencia dentro de un modelo que funciona de forma descentralizada, pero también jerarquizada a la manera de una suerte de malla que, con distinto grano, cubre todo el territorio del barrio.

En este escenario, la relación entre las diferentes agencias dedicadas al Trabajo Social es una relación de independencia coordinada, que se puede describir en base a un concepto de amplio uso por parte del colectivo de trabajadores: «la derivación». La derivación presupone que cada uno de los prestadores de ayuda - cada uno de los centros o asociaciones- está mejor equipado para atender ciertos problemas o proporcionar ciertas ayudas, por lo que es tarea de cada uno de ellos «derivar» al usuario que les interpela a la instan- cia más adecuada para la satisfacción de su demanda de ayuda. Pero no todos los prestadores de ayuda social disponen de la misma capacidad de intervención. Fundamentalmente, no todos tienen el mismo acceso a los así llamados «recursos», núcleo fundamental de la ayuda desde el modelo de intervención que se propone. La ley reguladora define la asistencia social básicamente como el desarrollo de tres tipos de acción formalizada (en el lenguaje utilizado «prestaciones»): prestaciones de carácter técnico, económico o material (todas ellas referidas al individuo). Las prestaciones económicas van desde la Renta Mínima de Inserción, a las ayudas de carácter puntual en concepto de «emergencia social», etc. Las prestaciones materiales son entre otras la atención residencial o diurna en centros creados al efecto, o bien la atención domiciliaria, la teleasistencia y alguna otra más. Las prestaciones técnicas son las más genéricamente definidas en la ley, que las cifra en «información», «diagnóstico», «asesoramiento», «apoyo» y otras intervenciones de los profesionales de los Servicios Sociales. La misma formulación ya deja entrever un aspecto que se constata en la práctica: la orientación de todo el modelo al ofrecimiento de unos «recursos-tipo» de carácter económico o asistencial. El tránsito ciertamente vertiginoso de la «promoción de una vida digna» a la gestión de una Renta Mínima de Inserción, una beca de comedor o el ingreso en una residencia de ancianos, se produce ya en el mismo texto normativo y queda aún más de manifiesto, cuando se observa en la práctica el funcionamiento de la red asistencial.

Desde este modelo no es extraño que el Centro de Servicios Sociales del ayuntamiento se consolide en la práctica como el prestador de servicios públicos de referencia en el área, fundamentalmente porque su capacidad de intervención dentro del modelo es infinitamente superior a cualquier otra instancia, ya que de él depende la gestión de los «recursos» (esas prestaciones económicas y materiales en las que se traduce la asistencia social básica pública). La atención al «usuario» ${ }^{5}$

5 «Derivación», «recursos»y «usuarios» son vocablos que forman parte del lenguaje característico del entramado de los Servicios Sociales, términos que incorporan ya la lógica constitutiva del modelo de atención implicado. 
que llega por primera vez al enorme edificio de la calle Paloma se canaliza como se detalla a continuación. Esta descripción nos permitirá sintetizar la estructura y el funcionamiento del centro municipal como nodo central de la red de Servicios Sociales.

Dentro de un esquema organizativo, que es prácticamente un calco de la estructura de los servicios públicos sanitarios, existe lo que se llama Primera Atención, cuyos profesionales son los encargados de recibir al nuevo usuario, de interpretar su problema o demanda y de «derivarlo» a aquella otra instancia -dentro o fuera del Centro de Servicios Sociales-que pueda ofrecer la ayuda requerida. La valoración del tipo de «demanda» se tiende a establecer en función de un esquema de demandas-tipo que se relacionan con otro esquema similar de recursos-tipos. Los recursos así formalizados son, por ejemplo, la citada Renta Mínima de Inserción ${ }^{6}$, una beca de comedor para la población infantil, una plaza en una residencia de ancianos o una guardería pública, una ayuda para la estancia en un balneario, etc. La gestión de la mayor parte de estas prestaciones, que hemos llamado «recursos-tipo», es tarea del segundo nivel de atención, por lo que, interpretada la demanda en estos términos, el trabajador social de primera atención no hará sino «derivar»al usuario hacia ese segundo nivel de atención social especializada. La gestión de estos recursos (de tipo económico y material) ocupa buena parte del tiempo de los profesionales del Centro de Servicios Sociales, habida cuenta que requieren procedimientos burocráticos que implican la realización de un mayor o menor número de instancias, solicitudes, informes y todo este tipo de lo que tantas veces se nombra «papeleo». Si el usuario sabe formular su demanda en los términos adecuados a esta escala de recursos, la tarea del trabajador de Primera Atención será entonces «derivarle» al segundo nivel de atención, y también-como «profesional de referencia» en el primer nivel del usuario a lo largo de todo su contacto con los Servicios Sociales-irle dando las instrucciones oportunas para la tramitación de la concesión del recurso en cuestión, instrucciones que suelen implicar la recolección de un cierto número de documentación, la cumplimentación de una solicitud y la presentación de todo ello, en los plazos e instancias administrativamente acordados para cada caso.

En ocasiones, sin embargo, este esquema de atención es inoperante, por diversos motivos. Es posible que el usuario no formule la demanda a partir de la solicitud de ninguno de los recursos disponibles, o quizás ninguna demanda como tal en absoluto. Tal vez el usuario no sea capaz de protagonizar la acción de solicitud de un recurso - por problemas de salud, de movilidad, de competencia lingüística en castellano, etc.; o quizás ni siquiera sea el sujeto de la intervención el que acude directamente a solicitar ayuda, por lo que se requerirá una visita al mismo en su domicilio para conocer las características de su problemática. Todos estos casos y algunos otros requieren un seguimiento posterior, que equivale a una intervención de mayor duración en el tiempo. El diagnóstico de esta situación por parte de los trabajadores de Primera Atención es el que les hace derivar a esos usuarios hacia los trabajadores sociales de zona que operan en el Centro de Servicios Sociales -y que están distribuidos por área geográfica de intervención- en función del lugar de residencia de los usuarios. El encuentro con un trabajador social no es inmediato, sino que funciona con un sistema de cita previa que puede demorarlo uno o dos meses desde el recibimiento en Primera Atención. Este dato nos deja entrever ya lo que va a ser una constante, aludida por todos los trabajadores de las distintas instancias de prestación social: la masificación de los servicios y el ritmo acelerado de trabajo al que se ven forzados estos profesionales.

Si éste es el procedimiento ordinario de prestación de servicios en el Centro de Servicios Sociales, existen una serie de excepciones: son los llamados «programas específicos», destinados a colectivos concretos de población previamente definidos (menores, mujeres maltratadas). Los programas corresponden a una definición y tratamiento de pro-

${ }^{6}$ Una prestación económica de carácter asistencial para cubrir necesidades básicas de familias con pocos recursos. 
blemas sociales-tipo o colectivos-tipo considerados como especialmente necesitados de protección y ayuda pública. En la medida en que se entiende que van a necesitar seguimiento previo, los usuarios que se encuadran en estos programas no pasan por Primera Atención, sino que son directamente atendidos por los responsables de éstos. Además existen urgencias y emergencias, que responden a situaciones más o menos tipificadas en las que se requiere una intervención rápida. En el resumen de una de las trabajadoras de Primera Atención apunta:

[Además de las situaciones ordinarias] tenemos situaciones de urgencia que están codificadas: malos tratos, abandonos (...) un menor abandonado o un anciano (...) problemas de alojamiento como que por ejemplo se ha caído el edificio de al lado y tienen que desalojar su casa (...) Pues viene Servicios Sociales y les pagan el hostal un par de días o tres hasta que se busca otra solución. Luego problemas de protección social o salud, una señora que está en el hospital y le van a dar de alta y necesita una residencia temporal porque no puede permanecer ni en el hospital ni en el domicilio. Luego emergencias: un incendio, una explosión (...) también nos llegan. O te llama la trabajadora del INSALUD que una señora encamada necesita una ayuda a domicilio urgente (...) cosas así.

De esta manera, la función del centro de Primera Atención es la de filtrar los casos que necesitan una mayor profundización y un tratamiento más dilatado en el tiempo, que se separan de aquellos cuya demanda puede ser resuelta en ese encuentro puntual o desplazada a otras instancias exteriores al Centro de Servicios Sociales (centro de salud, ONGs, asociaciones de vecinos, asociaciones de caridad, etc.). La Primera Atención funciona con un sistema de cupos diarios. A las nueve de la mañana de cada día laborable se abren los cupos y se entregan citaciones para nueve personas por cada trabajador, que obtienen cita para ese día. Algunos se vuelven a casa sin cita y tendrán que volver otra mañana temprano. Los que la consiguen tienen que esperar, los últimos incluso varias horas, antes de que se les atienda y en ocasiones sin llegar a conseguirlo debido a que los trabajadores pueden verse obligados a visitas imprevistas -urgencias, emergencias, trámites varios- que, programa- dos sobre la marcha sobre el tiempo total de trabajo, disminuyen ineludiblemente el disponible para la atención de los usuarios que se llegan al Centro de Servicios Sociales. Todos estos elementos de la situación de estos profesionales expresa una limitación, muchas veces vivida como impotencia, derivada de la cantidad ingente e imparable de trabajo a la que deben hacer frente y el tiempo limitado que, por lo mismo, pueden dedicar a cada caso concreto. «El problema principal -nos dirá una trabajadora de este servicio-es sin duda y fundamentalmente el nivel altísimo de trabajo y que en Primera Atención te sueles quedar con la sensación de que no has resuelto bien el problema». Estas condiciones de trabajo expresan también claramente la reducción a la que quedan sometidas las que la ley llama «prestaciones técnicas» y atribuye a los profesionales dentro de la institución: a la gestión de las prestaciones económicas y materiales ofrecidas a título individual (al «usuario»; se ve más claro ahora el sentido implícito de este término), que son el eje fundamental del modelo de intervención vigente.

Además de esta limitación -debida a un exceso de trabajo que tiene cada profesional, $y$ que obliga a ritmos juzgados como demasiado rápidos de interacción con el usuario-, se tiene una sensación permanente de que «no se llega» a toda la población necesitada de ayuda social. En primer lugar, se atiende sólo a los que motu propio vienen a la consulta o a aquéllos a los que se accede a través de un aviso de urgencia hecho por algún vecino, el juzgado, la policía, etc. El que sea ésta la vía de acceso les hace perfectamente conscientes a los trabajadores de la ayuda social de que es precisamente a los problemas más graves de exclusión a los que no llegan, a aquellas personas cuyas competencias y capitales -sociales, familiares, vecinales, de salud, culturales, etc.- les dificultan no sólo el vivir cotidiano sino también el «hablar el idioma de los Servicios Sociales», y el constituirse así como «usuarios» de éstos. En ese sentido los Servicios Sociales, ajustados a una formalidad burocrática y constantemente desbordados por la demanda, no pueden ser casi nada más que gestores de prestaciones económicas (directas o indirectas) al servicio de individuos -no de grupos ni de colectividades- que se encuen- 
tren en situación de demandarlos. La distancia que separa a una persona con dificultades cotidianas, derivadas de unas condiciones de exclusión o marginalidad social, de un usuario de los Servicios Sociales públicos, es muchas veces difícil de salvar.

Los principales colectivos de «usuarios» potenciales en Lavapiés son: por un lado, los nuevos inmigrantes y, por el otro, la población anciana, especialmente la que vive sola y lejos de su familia. La relación de ambos grupos con los Servicios Sociales es diferente, a decir de los trabajadores de los mismos. Muchos inmigrantes que carecen al llegar de gran parte de los medios de vida cotidianos, pronto se familiarizan -usualmente a través de su propia red social de compatriotas-con la existencia de los Servicios Sociales como conjunto de prestaciones a las que pueden acceder y son, en este sentido y en general, usuarios informados y ágiles ${ }^{7}$. Una trabajadora social, esta vez del Centro de Salud, nos dirá: «Vienen superinformaos (...) un inmigrante lo primero que hace es ir a ver a la asistente social, sin más problema. Al contrario [de pasivos] son muy reivindicativos». A pesar de todo, una categoría de los mismos, los que carecen de papeles -son por lo tanto «ilegales» de acuerdo a la definición administrativa estatal-apenas tienen derecho de acceso a alguno de los recursos tipificados (poco más que a becas de comedor para sus hijos en edad de escolarización obligatoria). Por ello, aunque acudan al Centro de Puerta de Toledo, allí no podrán sino derivarlos a aquellos prestadores de ayuda que, como la confederación de entidades de acción social de la iglesia católica, Cáritas, son el último recurso en el que obtener algún alimento o prenda de vestir.

¡Hombre!, un inmigrantes sin papeles (...) si tú tienes permiso de trabajo o eres español te puedo gestionar una Renta Mínima de Inserción, por ejemplo, pero si no (...)i búscate la vida! Porque no te vamos a poder gestionar nada, te vamos a poder dar una beca de guardería o de comedor si tienes algún menor, pero si no ¡búscate la vida! porque aquí no hay nada (...) Los derivamos a asociaciones (...) Cáritas, ese saco roto para ayuda de alimentos y cosas así (Trabajadora social del Centro de Servicios Sociales).
La población anciana en Lavapiés, sin embargo, desconoce mayoritariamente la función de los Servicios Sociales y no se ubica como usuaria de la misma. Acostumbrados a unas condiciones difíciles -urbanísticas, por ejemplo, en las infraviviendas del barrio-, los ancianos raramente buscan ayuda cuando esa dificultad se intensifica con el envejecimiento y la lejanía o el abandono familiar, y con poca frecuencia lo hacen en el ámbito de la Administración. En muchos de estos casos sólo cuando se trata de verdaderas situaciones de emergencia, generalmente con la mediación de algún vecino, la policía o la propia familia, es cuando estas poblaciones entran en contacto con los Servicios Sociales. La implantación de éstos como una suerte de malla territorial, y el gran número de recursos pensados para la población anciana (residencias, centros de día, ayuda a domicilio, teleasistencia, etc.) hacen, no obstante, que cada vez sean más conocidos y demandados por las personas más mayores del barrio, entre quienes la comunicación «boca a boca» y las buenas relaciones personales con alguno de los profesionales, parecen ser las vías más frecuentes de conexión con el entramado de los Servicios Sociales.

Ellos han vivido así toda la vida ¿no? La diferencia es que antes tenían capacidades físicas y ahora no. Y ahí están con la mierda, con esa cutrería de vida, pero ellos están adaptados a eso (...) Es gente muy de barrio, a nivel de vecinos (...), pero eso está cambiando porque están teniendo problemas en las casas, se están desconectando de su propio barrio, se están deprimiendo (...) Ahí entran mucho en juego las auxiliares de ayuda a domicilio que son ahora mismo las cuidadoras de estas ancianas, que a lo mejor los hijos los tienen en otro barrio o en el extrarradio (...) Entonces la gente también va conociendo un recurso y lo demanda, que antes a lo mejor, pues, aguantaban. (Trabajadora Social del Centro de Salud de Lavapiés).

Yo, pedir no he pedido nunca, pero el año pasado sí que fuimos a esto de la asociación [se refiere al reparto de alimentos de la asociación de vecinos La Corrala] que daban comida (...) iban todos los inmigrantes y oímos que nosotras también podíamos y entonces también fuimos (Vecina del barrio, ochenta años).

\footnotetext{
${ }^{7}$ Con muchos matices en función del género, la edad, el lugar de origen, etc. del inmigrante.
} 
En Lavapiés hay mucha gente muy mayor, ochenta y pico (...) y todos se conocen, porque estás a veces con las visitas y todos son como una gran familia y vas a ver a no sé quién y pasa la fulanita me vienen a ver a mí no porque les haya dicho el médico o la enfermera, sino porque les han dicho: «mira, vete a verla que me ha arreglao no se qué». Ya es el boca a boca. (Trabajadora social del Centro de salud).

Además del desconocimiento, el prejuicio, o la falta o pérdida de habilidad o capacidad para «hablar el lenguaje» de los Servicios Sociales, la masificación de éstos, que obliga a largos compases de espera y a una inversión considerable de esfuerzos (desplazamientos, atención, memoria, etc.), contribuyen también a que el número de usuarios no refleje ni la profundidad ni la extensión ni la heterogeneidad de la «problemática social» del barrio.

\section{La relación entre profesionales: lógica burocrática y frustración}

Además del Centro de Servicios Sociales del ayuntamiento existen, como vimos, otros trabajadores sociales dependientes de otras áreas administrativas o bien de asociaciones barriales independientes que desarrollan proyectos muchas veces con financiación pública. La relación entre todos estos agentes, si bien de independencia, se aproxima a una especie de implícita jerarquía de facto, que otorga preeminencia al centro del Ayuntamiento porque es, a través del mismo, como se gestionan gran parte de los recursos que se ofrecen como la vía principal de intervención o ayuda social. Estos "grandes recursos» - de acuerdo el modelo de intervención subyacente-, que tienen básicamente que ver con una ayuda económica al beneficiario, se complementan con otra serie de actuaciones, que la misma lógica institucional tiende a caracterizar como de menor importancia, muchas de las cuales las realizan específicamente las asociaciones: iniciativas del tipo «bolsas de trabajo», oferta de cursos y cursillos, espacios de encuentro y otros proyectos de convivencia, reparto de alimentos o de ropa, etc. Recursos complementarios que -se entiendepueden dar servicio a ciertos usuarios, descongestionando al Centro municipal y sirviendo, también, como última posibilidad, para aquéllos para quienes no se contempla el ac- ceso a los «grandes recursos» de carácter más directamente monetario.

Las relaciones entre los distintos trabajadores sociales, bien de dentro o de fuera de la Administración, pese a la práctica general de la «derivación» de usuarios de unos a otros, presentan un carácter ambiguo. El exceso de trabajo minimiza en gran parte la disponibilidad de tiempo para la relación transversal entre profesionales. Este reiterado argumento, que es en buena parte cierto, sin embargo no es suficiente para explicar el tipo de relaciones que se producen ni la causa de algunas de ellas. En primer lugar, son los trabajadores del centro municipal -excepto en casos concretos de buenas relaciones establecidas sobre la base de la simpatía personal-, los que resultan de más difícil acceso para los técnicos que trabajan en otras instancias de la Administración o de fuera de la misma.

Yo estoy contenta de la forma en que desempeño mi trabajo pero sobre todo es la falta de relación con la Administración (...) como que se podría hacer mucho más canalizando las ayudas de diferente manera, con un contacto más (...) porque el contacto que tenemos ahora es porque quiero yo hacerlo ¿sabes? O porque algún trabajador del Centro de Servicios Sociales lo pueda hacer (...) no porque la Administración (...) intente poner su enlace. (...) Supón que además tienen mucho trabajo, tienen mucho trabajo, ahora mismo en el Centro de la Paloma -es un suponer ¿no?- no estoy yo para perder el tiempo llamándote y no sé qué cuando tengo siete personas hoy y además tengo que ir a (...) (Trabajadora social de la Asociación de Vecinos La Corrala).

Esta falta de disponibilidad es sintomática de una jerarquía en las instancias de prestación de ayuda social, que opera con más fuerza en escala vertical. El acceso a los jefes, supervisores y directivos es más difícil que la comunicación que se produce entre los trabajadores «a pie de calle». Las relaciones que se pueden producir, y de hecho se producen, entre éstos y que dan en ocasiones lugar a constantes ideas de proyectos nuevos de intervención social, chocan una y otra vez con la lógica sectorial y vertical del entramado administrativo, así como con el conservadurismo que caracteriza a la lógica burocrática, en donde el énfasis en la estructura formal de los 
procedimientos establecidos tiende a frenar la dosis de informalidad e improvisación que exige la puesta en marcha de intervenciones novedosas y mejor «adaptadas al terreno». E1 diseño de los programas sigue generalmente un cauce vertical, de arriba abajo, que sitúa a los trabajadores de base como meros gestores de los mismos. Las posibilidades de que su iniciativa y experiencia se ofrezcan para modificar o crear programas se estrellan en demoras o en negativas, sin grandes explicaciones, de las instancias jerárquicas superiores, generando no pocas frustraciones entre los trabajadores de base más activos.

Las relaciones horizontales entre trabajadores de distintos sectores de la Administración son también difíciles; en palabras de una voluntaria de Cáritas: "porque muchos se piensan que estás interfiriendo en su trabajo o enmendándoles la plana y no les gusta».

Con Servicios Sociales [se refiere al Centro de Servicios Sociales municipales] (...) a lo mejor el médico iba a un domicilio, que había una persona encamada, sola, y se planteaba: «mira, que esta persona necesita una ayuda a domicilio». Yo cogía el teléfono: «oye mira, que tal médico o tal enfermera están haciendo una serie de curas y me han dicho (...)». Entonces yo sabía que esas historias no les gustaban, como si yo les estuviese mandando y yo no era mandar sino (...) tienes que andar detrás como pidiéndoles un favor. Y alguna vez fui a hablar con la jefa de este tipo de problemas tan absurdos y prácticamente me frenó en seco (...) que esas cuestiones de coordinación (...) bueno, que las teníamos que elaborar más despacito (...) entonces tienes que tener un tacto increíble, un tacto increíble. ¿Por qué? Porque hay compañeras -y no se puede generalizar- que están dentro de su ego, su profesionalidad, que su vida es ser asistente social, y a lo mejor la gente con ese profesional no conecta, porque no le llega lo que le cuenta, y a ti te lo cuenta y tú le indicas [al profesional] una cosa que has captado, y es como si te estuvieras entrometiendo en su trabajo. Entonces la cuestión de la coordinación es a veces un poco difícil por esa cuestión. Lo más fácil es seguir por tu ruta, aunque el circuito total sea un puro absurdo (Trabajadora social del Centro de Salud).

Como efecto de estas dinámicas, la sensación general resultante entre los técnicos de calle, sobre todo entre los que viven la situa- ción con mayor frustración, es la sensación de «el que se mueve pierde»: el que propone, critica, busca contactos o diálogos horizontales o interpela a sus superiores con propuestas que no le corresponde realizar, esto es, va más allá de su papel de gestor de recursos o de adecuación de demandas-tipo a recursos-tipo entre los que acceden a ellos como «usuarios».

Nosotros, además, es que tenemos dos jefes. Uno, que es el que nos coordina como mediadores que somos a nivel de mediación y, el otro, que es en este caso la jefa de sección. Entonces es que hay que ponerse de acuerdo entre las dos jefas que tenemos y no es como una sola. Entonces hay proyectos que están más enfocados a la mediación y aquí, en Servicios Sociales, todavía no lo ven o viceversa. Entonces hay que mediar también ¿no?, en la Administración (sonrisas) (...) No estamos preparados todavía, ipues el año que viene! (...) Hay proyectos que se quedan por burocracia un poco parados. Ahora estoy con un proyecto que es un proyecto de talleres en el ámbito socio-sanitario, con otra trabajadora (...) Lo hemos preparado, hemos mandado una carta de presentación a la directora-gerente y hemos hecho el esbozo de lo que queremos hacer. Le pareció interesante, estaba muy contenta pero de repente dejó de llamar, no puedo localizarla, siempre está reunida. Hablé con mi jefe de sección y le dije: «yo ya no puedo más. Que es que está preparao, está solamente para a ver cuándo quedamos con los profesionales para una charla con ellos y empezar a hacerlo». Y me ha dicho: «bueno, pues, espera a que te llame». Y en ello estoy (...) me da pena porque claro cuando ella me llame, si está muy ocupada o ha visto que a lo mejor no le interesa porque pueden ser las dos cosas (...) también es muy difícil de localizar pero luego pensé, un fax o a través de la jefa de sección que está permanentemente allí (...) y cuando hablé con ella estaba interesada pero luego (...) no sé. (Mediadora Social del Centro Comunitario de Lavapiés).

Los trabajadores de base, desbordados de trabajo y por el «papeleo»-lo que ya es suficiente desincentivo, como nos decía una trabajadora de Primera Atención: «si además de toda la gente tengo que diseñar programas, me da algo»-, son implícitamente llamados al orden dentro de una lógica burocrática imperante que casa mal con el modelo de Trabajo Social que a muchos de ellos les gustaría desarrollar, el modelo que despertó su afición 
por una profesión que, en muchas ocasiones, se vivió y aún se vive pese a todo, más como una verdadera «vocación» que como un «trabajo». Llamadas al orden se producen a veces de manera implícita, lo que contribuye a acrecentar un cierto sentimiento de «soledad frente a la Administración». De este modo nos refería una trabajadora su traslado forzado de Lavapiés argumentado en base a su «exceso de trabajo». Un supuesto exceso que, a su decir, era incongruente con que le hubieran asignado otra área urbana en lugar de Lavapiés, junto a otras en las que ya venía prestando servicio. La trabajadora pensaba que era: «mi trato directo con la gente, mis consultas alargadas hasta las cuatro, el que colabore con el periódico local del barrio lo que (...) molesta». Molesta, en su opinión, «en las altas instancias» y también a otros profesionales que se ajustan mejor al modelo burocrático de los Servicios Sociales. En ese sentido la trabajadora se resentía del comentario de una compañera, que la había culpado por «publicar panfletos políticos» en el periódico del barrio $^{8}$. Sea como fuere y al margen de la puntualidad del caso, lo que es patente es la ambigua situación de estos trabajadores de base de los Servicios Sociales que, dentro de la estructura de la institución, experimentan un malestar difuso, que le hace a una de ellas exclamar: «esto es como un tablero de ajedrez y nosotros no somos nada más que los peones». Un malestar que contrasta con la generalizada condición vocacional de su dedicación al Trabajo Social, que suele ser expresada con entusiasmo.

Yo en concreto tengo prioridad en ese campo, con esos chavales que son inmigrantes de segunda generación, porque yo misma soy segunda generación y sé lo que es, sé lo que se pasa. (Mediadora social con el colectivo marroquí en el Centro Comunitario de Lavapiés).
Yo empecé de pequeñita, hace tanto tiempo ya (sonrisas), entonces no era Trabajo Social ni nada: era voluntariado ¿sabes? En un colegio de niños deficientes, y era por Carabanchel, de donde yo soy, para ayudarles en el comedor (...) Es que a mí siempre me ha gustado las historias esas, había algo que me gustaba (...) Y yo pensaba que iba a hacer enfermería porque no sabía que existía lo del Trabajo Social. Y un día estaba yo en el centro cultural de mi barrio y me acuerdo que conocí a una chica que estaba haciendo Trabajo Social y me comentó de qué iba eso y me gustó muchísimo y dije: «iAnda! si eso es lo que yo andaba buscando, si nadie me había dicho que existía una profesión así», contando con la gente que realmente tiene problemas (...) Pues un poquito me abrió ella la luz y bueno, solicité esa carrera y te cuento, iba con unas ganas increíbles (...) ¡uffff.! (...) que me comía el mundo (...) y estaba haciendo todo el tema de la carrera y después todo el tema de las prácticas y disfrutaba mucho con ello. (Trabajadora Social del Centro de Salud).

Yo no sabía muy bien lo que quería hacer, pero me metí en esto y me gusta (...) También es duro ¿no? Pero le sacas satisfacciones (...) el trato con la gente. ¡Yo me lo paso muy bien! Estás en contacto con la gente, ves la realidad ¿no? Aunque luego sales a la calle y dices: «jolín! lo que estoy viendo ¿es la realidad? Todo parece tan normal iy con todo lo que hay aquí!» (Trabajadora del Centro de Servicios Sociales de La Paloma).

Sin embargo, es al modelo del gestor de recursos al que estos técnicos se ven impelidos a amoldar su práctica profesional. Presionados por una cantidad de trabajo que no pueden dejar de cubrir y enfrentados a una lógica que dispone la existencia de una serie de recursos-tipo (que exigen, además, un más o menos complicado trámite burocrático), estos trabajadores de los Servicios Sociales se afanan en sus consultas en «leer» 0 «traducir» la demanda del usuario, de acuerdo a esos recursos que se le pueden

${ }^{8}$ Lo que publicaba era una columna dedicada a narrar historias de problemáticas sociales con vocación de demostrar en cada caso cómo pueden superarse. Pero el periódico del barrio en el que lo hacía se significó en un determinado momento en contra de la política de rehabilitación implementada en el barrio, lo que sin duda tuvo que ver (probablemente entre otras cuestiones de carácter más personal) con la acusación de «tomar partido político» que formuló contra esta trabajadora una de sus compañeras, acusación que coadyuvó a la decisión de su traslado (forzado). Más allá del caso concreto, el episodio deja entrever cómo, en el seno de la institución, se formula como ideal una suerte de «lógica técnica» de carácter racionalista y abstracto, que se piensa alejada de la esfera-«cargada», «implicada», «sesgada»-de lo político. 
ofrecer. «Se convierten un poco en máquinas, pues canalizo tu ayuda y ya está, se vuelve un poco mecanizado ¿sabes?» Nos dice una trabajadora social de una asociación de Lavapiés, refiriéndose especialmente a los trabajadores del centro municipal (los que gestionan los recursos más importantes de acuerdo a la estructura del modelo de intervención, y los que encarnan el tipo ideal, en sentido weberiano, de profesional dentro de tal modelo). En el espacio de duración de la consulta, en una lucha contra reloj, el usuario tiene más posibilidades de «éxito» cuanto más hábilmente sea capaz de manejar el lenguaje en el que la Administración codifica la necesidad y la ayuda social.

La experiencia como voluntaria de una de estas esforzadas trabajadoras sociales ${ }^{9}$ me permitió la familiarización con la práctica cotidiana del modelo de intervención pública. Consultas atestadas, con horarios voluntariamente extendidos por la trabajadora para atender a quienes aguardaban en la sala de espera. La mesa llena de formularios para solicitar una cosa o la otra, cada uno con sus requisitos y con las direcciones a las que acudir desperdigadas por agendas y repartidas, escritas apresuradamente y sobre la marcha en post-it y pequeñas hojitas de block de notas. Forzado ritmo de charla entre el usuario y la trabajadora, mil veces interrumpido por el teléfono. Desesperados in- tentos de aquellos más perdidos o más débiles o con menos recursos de fijar en la memoria el día y la hora y el lugar al que debían acudir por una cosa u otra, preguntando una y otra vez a la trabajadora, ya cruzándose en la puerta con el siguiente para consulta, etc. El mismo cumplimiento de los procedimientos que el propio funcionamiento del modelo asistencial le exige al usuario -en materia de «papeleos», de estructuración de la interacción en marcos espacio-temporales muy pautados, etc.- es muchas veces muy difícil para éste. Por su parte, obligada por la presión de la demanda (bien presente cada vez que el abrirse o cerrarse de la puerta deja entrever la atestada sala de espera) a permanecer «atada a su consulta», la trabajadora social apenas puede echar mano, para ayudar a los usuarios sin las habilidades requeridas, de un cuerpo siempre escaso y fluctuante de «voluntarios»: algún vecino animoso, estudiantes de Trabajo Social en prácticas, jóvenes haciendo la prestación social sustitutoria del servicio militar (hasta su desaparición), etc. En los intersticios de las tipificadas demandas-recursos con las que la Administración construye la cuestión de la intervención sobre la marginalidad social, desbordan millones de ejemplos en los que la tremenda indefensión que significa la marginalidad social ${ }^{10}$ se enfrenta $-\mathrm{y}$ se reproduce- a la lógica burocrática y es-

${ }^{9}$ A diferencia de la relación que establecí con otros técnicos de la Administración (del sector urbanístico, por ejemplo), muy mediada por la lógica burocrática-administrativa de los permisos, peticiones y estructuración formal de los encuentros, fueron precisamente estos trabajadores sociales que llamo «vocacionales» los que menos procedimientos formales dispusieron a la hora de establecer una relación y una colaboración conmigo, incluso en su lugar de trabajo.

${ }^{10}$ Las limitaciones de espacio me impiden profundizar en un tema de radical importancia aquí, que no es otro que la misma producción social de la idea de «marginalidad», y del término «marginales» (o alguno de sus equivalentes, v.g. «excluidos») como aquél que nombra y define a los sujetos a los que se destina la ayuda social. «Marginal» es, por un lado, una categoría descriptiva que pretende nombrar a una variedad de sujetos definidos por una común condición precaria respecto a los elementos básicos sobre los que se funda -en nuestro contexto- la identidad social: unos mínimos medios materiales de vida (vinculados al trabajo, la renta o la vivienda), y una mínima estructura de apoyo y relación social (familiar, amical, vecinal...) en la que tejer vínculos afectivos. A esta condición precaria respecto a dichos elementos se suma, en muchos de los casos, una experiencia de rechazo social (derivada de esa misma precariedad y de sus múltiples corolarios) sostenida en el tiempo, que hace mella en la propia auto-identificación del sujeto, reforzando un habitus que, desde el punto de vista de la pauta social normalizada, no puede más que ser caracterizado como «disfuncional». De este modo, el término individuo o población «marginal» que opera a la base de todo el entramado de la asistencia social no sólo es descriptivo, sino también performativo, en tanto homogeniza a una serie de sujetos, situaciones y comportamientos dispares en un conjunto definido por una condición de anormalidad. En otra palabras, la asistencia social crea la «marginalidad» como una categoría de visión y división de la realidad social al tiempo que -pretende- aplicarse a hacerla desaparecer. Esta aporía está detrás de los dilemas y tensiones que viven gran parte de los trabajadores sociales, como figuras situadas en la frontera de la institución. 
tatal que en ocasiones se revela, en el desvarío de su impecable lógica procedimental, como una verdadera lógica demente. Atrapados en su malla, profesionales aplicados, gestores burocráticos y usuarios obligados a hacer de la necesidad virtud, conviven con otros trabajadores frustrados, «quemados» y heroicamente voluntaristas; también con «usuarios» indefensos y desorientados y, más allá todavía, con todo un desconocido rostro humano del sufrimiento social que nunca se convertirá en usuario de los Servicios Sociales municipales.

La cantidad de recursos «mal gestionados» -porque los usuarios no entregan los oportunos documentos en el lugar y la fecha exacta o porque olvidan las revisiones periódicas etc.- son un síntoma (no diremos que) de la ineficacia de la actuación institucional, pero sí de la existencia de todo un espacio en el que se pone de manifiesto la falta de adecuación entre un modelo burocrático de servicios y la realidad práctica y vital de las personas a las que se dirige. Un modelo que exige una cierta concepción y planificación del tiempo, una idea de exactitud, rigor, secuencia y, en definitiva, una serie de esquemas y habilidades cognitivas y procedimentales que se dan por supuesto y de las que, sin embargo, carecen en muchas ocasiones los «usuarios», bien por problemas de salud, dificultades con el idioma, diferencias culturales, problemas de relación social o por efecto mismo de toda una trayectoria social como «marginales» y el enorme impacto de ésta en la estructuración de la personalidad y en los modos de relación con el entorno. Este fenómeno sin hablar de las propias percepciones que de los mismos «Servicios Sociales» tienen los «usuarios», que no necesariamente coinciden ni entre sí ni con la propia representación que de sí misma produce la institución ${ }^{11}$. Esa falta de adecuación y de mecanismos de mediación (más allá de las habilidades del profesional situado en la frontera) entre la lógica burocrática y las lógicas sociales a las que se dirige, es entendida dentro del modelo de los Servicios
Sociales como una molesta serie de «fallos» o «errores», cuya culpa recae a menudo sobre el usuario, errores que se capean a regañadientes -«ipues ya, lo que nos faltaba!»entre el paternalismo («Bueno, a ver si te ponemos a alguien que te acompañe») y la amonestación ( $i \mathrm{iSi}$ es que se lo he dicho ya cincuenta veces cómo tiene que hacerlo!).

La falta de adecuación de los programas -en cuyo diseño apenas participan los trabajadores de base- a la realidad compleja y difícilmente «tipificable» de la necesidad social, no hace más que sobrecargar aún más el sistema y contribuir al estrés -mejor o peor asumido- de sus trabajadores.

El concejal no tiene ni idea de lo que yo hago aquí. «Pues atiende a la gente y le da solución a sus problemas». ¡Mentira!. Siempre tienes muchísimo trabajo para muchas cosas y más del que (...) por ejemplo, el tema de las mujeres maltratadas. Estamos hartos de oír en la tele que hay recursos para todas y aquí tienes una mujer maltratada por una urgencia, quieres buscarle un piso para esta noche y no hay. (...) Muchas veces es falta de recursos y otras de coordinación o definición de los programas (...) si la realidad es que hay muchas mujeres inmigrantes y sin documentos, la Comunidad Autónoma de Madrid, para conseguirle una pla$\mathrm{za}$, te pide que tenga documentación y ¿entonces? ¡Pues no hay! Y entonces tiene que ser únicamente a través de una asociación y para que la asociación tenga plaza para una mujer maltratada, tela. (Trabajadora de Primera Atención del Centro de Servicios Sociales).

No son infrecuentes las críticas de estos «técnicos del Trabajo Social» a los cargos directivos y políticos - de dentro de la misma institución o del ámbito más amplio de la política municipal, con referencia a «el alcalde» o a «los concejales». La misma tesis que enunciábamos al comienzo de este artículo -la que postula que, como dice una de estas trabajadoras: «al Estado, en realidad, no le interesa el Trabajo Social»- toma aquí la forma de una acusación particular contra ciertos gestores

11 En las entrevistas y conversaciones informales en el marco de mi tarea de voluntariado se puso de manifiesto numerosas veces la existencia de otras lógicas de percepción y valoración de la asistencia social muy distintas a las que se producen desde otros puntos de la red (del lado de los profesionales y técnicos). Sin embargo, los límites de este artículo, escorado hacia el análisis de la figura del trabajador social, no permiten dar a esa etnografía el espacio que merecería. 
políticos, con nombres y apellidos, o contra la «clase política» en general.

Nos tienen de apagafuegos. ¿Creerse ellos mismos toda la cuestión? No. No lo valoran. Entonces si yo me voy con grandes expectativas de cambio (...) estaría quemada. Es de todo esto de lo que hablan los profesionales de la ayuda. No. Soy consciente de la tierra donde piso (...) Sí, sí los médicos (...) los que están a pie de tierra conmigo, esos sí lo valoran cada vez más ¿eh? Cuentan muchísimo más conmigo (...) La cuestión de los de arriba, debería haber muchísimo más apoyo, muchísimos más recursos, empezando por recursos humanos, ¿entiendes lo que te quiero decir? La cuestión es que si yo realmente me paro a pensar de que por parte de ellos no estoy valorada, yo me habría quemado, haría lo mínimo posible, no me estaría hasta muchísimo más tiempo de lo que me estoy. Eso lo hago primero por mí y por la gente, que creo que la mayor valoración que puedo yo tener es por mi misma, es por lo que yo puedo conseguir con los demás, el día a día, sino yo no tendría (...) la chispa. (Trabajadora del Centro de salud).

La figura del trabajador social, profesión que muchos desarrollaron siguiendo una suerte de vocación, está sometida a una presión derivada del modelo de intervención que hoy define a los Servicios Sociales públicos. Falta de tiempo, exceso de trabajo, lógica reductora de la complejidad a problemas/soluciones «tipo», consideración de la «ayuda» básicamente como prestación monetaria, inaccesibilidad a gran parte de la problemática social, desincentivo del rol creador y crítico en beneficio del gestor, encorsetamiento de la relación con otros profesionales y superiores del ramo dentro de la lógica sectorial y jerárquica de la Administración, etc. A estas fuentes de tensión se suma el propio hecho de estar en contacto con problemas sociales, muchos de extrema gravedad ( Es que no te imaginas lo que hay detrás de las paredes de las casas, aquí bien cerca»). Esta continua exposición personal de los trabajadores sociales a situaciones difíciles los enfrenta a un dilema que varios de ellos nos refieren. Se trata de mantener la debida distancia respecto a esa potencial ansiedad profesional, «no haciendo tuyos los problemas de la gente». El Trabajo Social exige una suerte de desconexión men- tal que ha de funcionar al término del horario laboral, como única manera de preservar el propio equilibrio mental del trabajador. Este proceso, que normalmente se recorre con los años, puede desembocar, sin embargo y según algunos nos refieren, en la pérdida de una actitud de empatía con la gente y de una voluntad poco menos que entusiasta ( $\sin$ las cuales no es posible ni comprender la necesidad ni desplegar la ayuda en un marco de posibilidades limitadas). Siendo las notas características de la vocación del Trabajo Social, éstas pueden llegar a perderse con el desempeño de la profesión dentro del entramado institucional de los Servicios Sociales.

El que diga que no se implica (...)i mentira! Te implicas quieras o no; si eres un poquito sensible se te ponen los pelos así y, aparte, si no te implicas un poquito es que te da lo mismo todo, te pasan los problemas así (...) te resbalan. La cuestión es: ni implicarte tanto, tanto, que no puedas dormir por la noche, estar dándole vueltas porque la persona te ha pasado su problema y, entonces, eso no es la forma más objetiva de poder ayudar. Eso es, a lo mejor, la fase inicial, cuando te comes el mundo, no tienes (...) pero no eres Teresa de Calcuta (...) o ya, en el otro extremo, la gente que lleva unos años en la Administración, en las instituciones, que le empieza a resbalar y empieza a pasar. Y empiezan a pasar tanto que pasan demasiado. Y trabajas con problemas de la gente, pero es como si trabajaras con un papel o con un número (...) y no te llega. (Trabajadora social del Centro de Salud).

Es precisamente esta figura del «técnico distante», del burócrata de los Servicios Sociales, la que tiende a reproducir el modelo de intervención de Estado: la gestión de una serie de recursos-tipo que implica hacer corresponder unívocamente cada problemática con uno o varios (o simplemente con ninguno) de éstos, y una instrucción de los procedimientos adecuados para su obtención por parte del usuario correspondiente. No se trata de indagar en las causas -a menudo complejas- que están detrás de la expresión de un malestar tantas veces sólo vagamente referido por los usuarios, o narrado en una lógica sólo aparente que no puede dar cuenta de la verdadera complejidad, alcance o dirección de la causalidad subyacente al malestar. De 
hecho una de las características del modelo de intervención de los Servicios Sociales y de sus «profesionales» ${ }^{12}$, es su escasa consideración del usuario como sujeto agente que puede intervenir sobre su propia problemáti$\mathrm{ca}^{13}$. Un modelo que produce resquemores entre aquellos trabajadores menos adaptados. Reproduzco a continuación algunos fragmentos de entrevistas que expresan magníficamente esa colisión entre estilos y concepciones de intervención, así como el malestar de los profesionales cuya opción no es la sancionada por las estructuras y los procesos de los servicios sociales como conjunto articulado:

Muchas veces las alumnas ${ }^{14}$ de Trabajo Social vienen con una idea de que lo más importante en el Trabajo Social es tener muchos recursos y lo más importante es el ayuntamiento, los Servicios Sociales [el Centro de Servicios Sociales], porque lo tienen todo ¿entiendes? Cuanto más gestiones mejor. Cuando vienen a verme a mí se descabalan, no hay recursos como tales, muchas veces viene la gente sin saber por qué viene y tú tienes que averiguar qué es lo que les pasa, entonces realmente se dan cuenta de que realmente se puede intervenir desde otras ópticas, se puede intervenir de otra manera y los recursos no son ningunos, pero pueden ser a la vez todos (...) y se quedan... se les rompen los esquemas. Alguna alumna incluso me dijo (...) que como yo trabajaba le ha producido, que lo tuvo que dejar, un estrés increíble (...) que no lo entendía. Digo: «que no todo es tan hermético ni tan cerrado ni tan fácil de resolver». Mira, una señora que me vino a ver con un tema de pensión, pero de paso me cuenta que su hijo tiene un problema de complejos que no se relaciona. Pues vino el otro día para que conociera al hijo y a ver si lo podía poner en contacto con algún grupo (...) eso no se lo dijo a la doctora. Y a veces de las formas más tontas salen las cosas y eso es para mí lo importante, no el recurso ni la gestión, sino estar ahí, y es que muchas veces la gente ignora qué tiene.
El intentar que la persona tome conciencia de lo que le está pasando y decir: «voy a salir de ello», «tengo fuerza para salir de ello y sé que existen recursos y que esto era lo que realmente me pasaba y no lo que yo creía» (...) es de las cosas más importantes que puede haber. Eso es lo que se pierde por ir deprisa, entra la persona por la puerta: «a ver, qué le pasa». ¡Bum! ¡bum! Buscas qué hay para dar y ¡toma, esto! (...) Pues no, con que escarbes un poquito (...) a lo mejor te está verbalizando lo menos importante. (...) No esos compañeros que te vienen con lo profesional (...) Lo importante es poder conectar y que la gente misma saque lo que tiene dentro. Claro, todo tiene su porqué. A lo mejor esa señora tan gruñona que no quiere hacer ningún tipo de dieta, siempre de mala leche (...) hay que ver en qué condiciones vive, hay que ver que a lo mejor la familia la ha dejado de lado o que ella esperaba muchísimo más de la familia de lo que luego se ha encontrado, ansiaba la familia tradicional de toda una vida, que sus hijos eran los cuidadores como ella lo hizo, y se encuentra que ahora es todo muy grande, vamos todos muy deprisa, no tenemos tiempo para escuchar. Entonces es preguntar cómo te sientes. Porque yo a veces rompo un poco los esquemas porque les digo: «sí, vale, todo eso está muy bien pero tú cómo te sientes». Me dicen a veces: «qué, cómo, pero ¿es que no me lo vas a solucionar tú?». «Sí, pero todos tenemos capacidades y te pregunto a ti a ver lo que se te ocurre». Escuchar e implicar. Hay gente que te dice: «estoy muy sola». Y el problema mío no se cómo encajarlo ni dónde ni (...) o no me llevo bien con la hija o con los vecinos, entonces a quién se lo cuento: ¿al ayuntamiento?

\section{Marginalidad social: significado y efectos}

Del testimonio de estos trabajadores sociales se infiere cómo la situación de marginalidad -que coloca al individuo al margen o en el borde de los apoyos sociales que lo sostienen en cuanto tal- es una condición urbana que dificulta el acceso a los núcleos más básicos sobre los que se asienta la identidad perso-

${ }^{12}$ Este término fue el que utilizaron cuatro de las trabajadoras sociales que entrevistamos para referirse, con carácter despectivo, a este tipo de trabajador ajustado al tipo ideal del modelo de la institución.

13 En ese sentido el modelo de los Servicios Sociales reproduce el tratamiento del demandante como paciente, objeto o cuerpo enfermo, al estilo de la práctica institucional de la Medicina.

${ }_{14}$ No he comentado aún la absoluta y generalizada feminización del Trabajo Social como actividad profesional, que queda bien patente en el hecho de que todas las entrevistadas para este trabajo fueron mujeres, menos un hombre. Esto se debe, claro está, no a una selección consciente o inconsciente por mi parte, sino a que la inmensa mayoría de las trabajadoras de esta red eran mujeres. 
nal ${ }^{15}$. La falta de trabajo, de domicilio, de «papeles»y y las trayectorias sociales marcadas por combinaciones de unas y otras carencias, que caracterizan la figura de aquellos en situaciones más graves de exclusión, se traducen a menudo en un complejo malestar y aún en un desorden psíquico y físico, con el que los trabajadores de la asistencia social se encuentran a menudo ${ }^{16}$. Paradójicamente, la «inseguridad ciudadana» (esa figura estelar del imaginario urbano), en ningún sitio se vive con tanta intensidad como entre los «marginales» de la ciudad, que soportan además, como «clases peligrosas», el estigma y la culpa de una condición marginal cuya esencia, por decirlo así, no les pertenece a ellos sino a la ciudad como específica espacialidad social, como lugar específico. Una inseguridad expresada en actitudes y sentimientos de retraimiento, indefensión, temor y hasta terror, manifestados muchas veces en estallidos nerviosos o malhumorados o en muestras repentinas de desconfianza, que suponen una verdadera corporización de la condición marginal (un habitus marginal por así llamarlo), que a menudo observé entre las personas que tuve la oportunidad de conocer y visitar, como voluntaria dentro de esta red de asistencia: varias ancianas gruñonas y exigentes, alguna depresiva voluntariamente encerrada en casa, una ex-drogadicta acostumbrada al engaño y la agresividad como formas de lidiar con el pánico al señalamiento y el rechazo, un desempleado crónico de edad madura incapaz de seguir cualquier rutina cotidiana de las prescritas por su asistente social, una mujer (con una larga trayectoria de maltratos y acogimientos institucionales) absolutamente hermética; tantos profundamente ofendidos por las largas esperas o las actitudes paternales (a pesar de todos los cuidados empleados), otros agradecidos hasta el llanto por ser admitidos a consulta, o temerosos por no estar entendiendo las instrucciones recibidas, etc. Son apenas esbozos de algunas de las personas a cuyo conocimiento debo, no ya la idea, sino la certeza sentida en la violencia del impacto del encuentro con lo distinto, de que lo que habitualmente entendemos por «comportamiento (siquiera mínimamente) racional», en el cual fundamos nuestra relación con los demás y con el mundo, está asentado sobre ciertas condiciones sociales ligadas a una situación de privilegio, al margen de las cuales tal comportamiento sencillamente no puede existir. Y se trata de una inexistencia que genera gran sufrimiento a quien la padece. Esto es parte de la vivencia cotidiana de eso que llamamos «población marginal». En la medida en que la misma estructura de la interacción asistencial contribuye a la reproducción de esa experiencia, no puede dejar de ser cómplice de la (re)producción de esa línea divisoria que continuamente separa a «los marginales» de los que estamos del lado de la razón y el juicio; cómplice del efecto de exclusión que dicha división implica.

Otra de las características que definen el tipo de intervención social que el Estado efectúa a través de sus Servicios Sociales se refiere al tratamiento individual de las problemáticas, que minimiza o directamente excluye el trabajo con grupos (familiares, vecinales, laborales etc. etc.). Si la marginalidad o exclusión social se caracteriza por ser una situación relacional -en y respecto al conjunto de la ciudad-, el tratamiento individualizado de las mismas las considera sólo como un dato, como un resultado, como una carencia de recursos. En consecuencia, la intervención que

15 Una identidad individual que es plenamente social, ni qué decir tiene. Resulta curiosa esa dicotomía que tradicionalmente separa y opone al individuo y la sociedad, considerando el fundamento de lo individual aquello que escapa o queda al margen de la constitución social del sujeto. Pero decir individuo, decir sujeto, es precisamente predicar de alguien que está «sujeto a» aquello que al limitarlo, lo define e individua. El límite no solamente -como suele pensarse-impide, también hace posible, crea, «sostiene».

16 La condición marginal dificulta, por ejemplo, la emergencia de sujetos urbanos en lo que es una de las dimensiones características de éstos (en nuestro contexto socio-cultural): el ser sujetos de derechos colectivos. Es por ello por lo que no sorprende que los sectores vecinales que más frecuentemente se expresan en términos de derechos ciudadanos, y que plantean su articulación grupal y su intervención en la esfera de la política en esos parámetros, no sean los sectores vecinales en una situación más extrema de marginalidad social. Es lo que hemos visto, en el mismo Lavapiés, a propósito de la contestación vecinal a las políticas de la rehabilitación urbanística (Cañedo, 2006). 
proponen los Servicios Sociales se refiere, mera y principalmente, a la dotación de un recurso externo -económico o asistencial-que se corresponda con la sintomatología presentada por el usuario individual, en la que no se busca profundizar. La ayuda, la asistencia o la prestación -es significativo como en estas redes institucionales estas palabras han sustituido a otras más antiguas como "solidaridad»o «justicia»-, queda reducida a una asignación económica, y sus destinatarios no son ya pensables desde figuras de comunidad (el pueblo, las clases populares), sino como un mero agregado de individuos aislados «al margen» de la normalidad.

Esta preocupación por la «correspondencia» síntomas/recursos y por la tramitación burocrática que éstos exigen, explica una actitud característicamente señalada en los profesionales más adaptados al modelo: rigidez, formalismo, culpabilización de los propios usuarios, cuando no se adaptan a las exigencias de la intervención, desconfianza de los compañeros demasiado «informales», escaso interés en la crítica o el diseño de nuevos programas. Es la figura de este profesional -que más allá de las personas concretas que la encarnan dibuja la figura-tipo que el modelo de los servicios sociales construye ${ }^{17}-$, la que emerge como el blanco de las críticas de los trabajadores sociales menos adaptados, o la de aquellos que ven la adaptación como un fracaso o una perversión de la función social del Trabajo Social:

Imagínate tú, que yo llevara al Ayuntamiento un informe médico porque la ancianita no puede salir iy luego echarle una bronca a la ancianita de a ver por qué me había dado a mí el informe! Son cosas que (...) qué pasa, ¿que ella es muy profesional y todo este tipo de cosas? (Trabajadora social del Centro de Ancianos).

Yo les digo a veces: «mira, es que para eso tienes que ir allí». "Que no, que no quiero ir (voz llorosa), es que parece que me está echan- do la bronca». Es el talante, el talante y decir: «tú estás en la mierda casi porque te lo has buscao». Por favor, no se puede tratar así a la gente. (...) Algunos deberían hacer un máster en habilidades sociales, un máster en comunicación. No todo el mundo ¿eh?, pero este tipo de trabajos queman mucho, al final no te implicas nada y tratas lo menos posible a la persona. También porque a lo mejor todos estamos demasiado abrumados y yo creo que también porque da miedo (...) Hay determinadas cosas que da miedo hacerlas, coordinarse, ver qué hay más allá de (...) (Trabajadora social del Centro de Salud).

\section{Conclusiones: ¿la dimisión del Estado?}

La frustración de los trabajadores «vocacionales» que están constante, sutil y cotidianamente desautorizados por la lógica global de intervención, se incrementa si tenemos en cuenta otro factor que incide sobre la constitución profesional de la actividad del Trabajo Social. Si muchos de los trabajadores sociales son funcionarios ${ }^{18}$ o contratados estables por la Administración, existe también un gran número de trabajadores sociales cuya estabilidad laboral es sumamente reducida (contratos precarios, bajos salarios). Becarios, profesionales adscritos a proyectos de financiación pública gestionados por asociaciones (...) como una becaria del Centro de Servicios Sociales municipales nos decía: «En el Trabajo Social hay mucho trabajo, pero muy pocos puestos de trabajo». Para estos trabajadores precarios del Trabajo Social, ni qué decir tiene que los problemas frecuentes de estrés, frustración, depresión o genérico malestar-como el de tantos de sus usuarios- se incrementan. Por si aún fuera poco, una última consideración muestra hasta qué punto el Estado habilita a sus trabajadores sociales para desempeñar una tarea para la que no les dota de medios adecuados ni suficientes. Porque entre los -tan caros- «recursos» que el Estado dispone para la ayuda social brillan

17 Se trata de una figura estructural que es independiente de las características personales de quienes la ocupan. No estamos de ningún modo juzgando aquí a una fracción de los trabajadores sociales madrileños, sino tratando de dar cuenta de la lógica social que sanciona positivamente un determinado tipo de perfil profesional.

${ }_{18}$ Una cuestión interesante en la que no he profundizado es la de la vinculación entre los distintos perfiles de los trabajadores sociales de la red y las figuras específicas de contratación administrativa, considerando la especial relevancia que adquiere la categoría de funcionario del Estado. 
por su ausencia precisamente aquéllos que están, en lo que es una opinión coincidente entre los trabajadores sociales, a la base de la mayor parte de los problemas: el trabajo y la vivienda. También la documentación -en puridad, el estatus de ciudadano- en el caso de la inmigración definida como ilegal. ¿Cuál puede ser la incidencia de los Servicios Sociales públicos en el tratamiento de la exclusión social si su acción se hurta precisamente a la intervención sobre los mecanismos que la producen? ¿No apunta este fenómeno a la lógica de reproducción de determinado modelo de ciudad, que está basado en la producción, necesariamente simultánea, de centralidad y marginalidad social y espacial?

El tratamiento de la marginalidad a través de una provisión de recursos económicos a título individual -en lo que básicamente consiste la intervención de los Servicios Sociales- oscurece la lógica social que vincula las prácticas cotidianas de reproducción de la ciudad como espacio social con la producción de la marginalidad urbana. Ésta, así desconectada de las condiciones sociales de su emergencia, se vuelve una realidad inasible en la ciudad; una realidad que genera una gran ansiedad colectiva al constatarse cómo, inexplicablemente, se reproduce como un cáncer en el tejido urbano a pesar de todos los esfuerzos por hacerla desaparecer. Es entonces cuando, muchas veces, el «marginal usuario de los Servicios Sociales» («vago», «exigente», «una carga para la sociedad»), se convierte potencialmente en el chivo expiatorio de ese malestar urbano, en el culpable de su misma situación marginal, en la viva encarnación de todos los horrores de la ciudad. En un texto colectivo que analiza lo que Pierre Bourdieu, el director del trabajo, llama «lugares difíciles» -ejemplos de los cuales son los conjuntos habitacionales de las periferias de las grandes ciudades francesas-, se registra una transformación del modelo de ayuda del los Servicios Sociales públicos en una línea similar a la aquí descrita (si bien las banlieues poco tienen que ver, en otros sentidos, con Lavapiés). Habla el autor francés de: «la sustitución de las antiguas formas (...) por la ayuda directa a la persona» que «reducen la solidaridad a una simple asignación financiera que sólo apunta a permitir consumir sin procurar orientar o estructurar el consumo». En términos muy duros continua seguidamente Bourdieu caracterizando la que llama «la dimisión del Estado, en perfecta conformidad con la visión liberal» y con la producción de una «miseria material y moral que es la única consecuencia cierta de una «realpolitik económicamente legitimada», a la que acompaña el paso:

De una política de Estado que aspira a actuar sobre las estructuras mismas de la distribución a otra que sólo pretende corregir los efectos de la distribución desigual de los recursos en capital económico y cultural, es decir una caridad de Estado destinada, como en los buenos tiempos de la filantropía religiosa, a los «pobres meritorios». Las nuevas formas que asume la acción del Estado contribuyen así, con el debilitamiento del sindicalismo y las instancias movilizadoras, a la transformación del pueblo (potencialmente) movilizado en un agregado heterogéneo de pobres atomizados, de «excluidos», como los llama el discurso oficial, a los que se mencionan sobre todo (si no exclusivamente) cuando «plantean problemas» o para recordar a los «acomodados» el privilegio que representa tener un empleo permanente (Bourdieu, 1999, p. 163).

Sin pretender extraer las mismas conclusiones de un análisis tan limitado como el que aquí presentamos, el análisis de Bourdieu nos sirve para delimitar un horizonte de lectura en el que advertir la pertinencia política del análisis crítico de los modelos de intervención social y de los efectos que producen. También para advertir, en las tensiones y contradicciones vividas por un colectivo, algo que va más allá de una suma desconectada de situaciones y vivencias expresadas en opiniones y emociones personales, y que podemos tomar como analizador del modo en el cual la desigualdad se (re)produce en el corazón mismo de nuestro sistema socio-político.

\section{Referencias bibliográficas}

Bourdieu, P. (1999). La miseria del mundo. Madrid: Akal. Bourdieu, P. (1993. El sentido práctico. Madrid: Taurus. 
Caldeira, T. (2000). City of walls. Crime, segregation and citizenship in Sao Paulo. Los Ángeles: California University Press.

Cañedo, M. (2006). Lavapiés, área de rehabilitación preferente. Políticas culturales y construcción cultural. Tesis doctoral inédita. Madrid: Universidad Complutense.

Castells, M. (1981). Crisis urbana y cambio social. Madrid: Siglo XXI.

Comunidad de Madrid, Ley 11/2003, de 27 de marzo, de servicios sociales de la Comunidad de Madrid.

Hauser, P. (1902). Madrid bajo el punto de vista médico-social. Madrid: Sucesores de Ribadeneyra.

Levy, J. P. (1987). Centres villes en mutation. Paris: CNRS.

López Sánchez, P. (1986). El centro histórico. Un lugar para el conflicto. Barcelona: Geocrítica. Universidad de Barcelona.

Mur Petit, R. (2008). Una visión de la Barcelona pobre, excluida y asistida por la política social y los salarios de renta mínima. En La metaciudad: Barcelona. Transformación de una metrópolis, pp. 131-156. Barcelona: Anthropos.

Parreño, J. M. (sep. 1986). Lavapiés: playa de naufragios. Alfoz (32), 45-48.

Pérez Quintana, V. (2010). Lavapiés. Intervención y rehabilitación, 1998-2008. Madrid: EMV, FRAAVV y A.V. La Corrala.

Smith, N. (1996). The New Urban Frontier. Gentrification and the Revanchist City. Londres: Routledge.

Stolcke, V. (Feb., 1995). New Boundaries, New Rethorics of Exclusion in Europe. Current Anthropology, 36, 1-24.

Troitiño Vinuesa, M. A. (1992). Cascos antiguos y centros históricos: problemas, políticas y dinámicas urbanas. Madrid: Ministerio de Obras públicas y Transportes.

Vilas, C. M. (1979). Política Social, Trabajo Social y la cuestión del Estado. Revista de Acción Crítica, 6, Lima.

Wacquant, L. (2001). Parias urbanos. Marginalidad en la ciudad a comienzos del milenio. Buenos Aires: Manantial. 